\title{
APRENDIZAGEM BASEADA EM PROBLEMAS: UMA EXPERIÊNCIA NO ENSINO DE QUÍMICA
} TOXICOLÓGICA

Renato Matos Lopes*

Laboratório de Comunicação Celular, Instituto Oswaldo Cruz, Fundação Oswaldo Cruz, Av. Brasil, 4365, $21040-360$ Rio de Janeiro - RJ, Brasil

Moacelio Veranio Silva Filho

Escola Nacional de Saúde Pública Sérgio Arouca, Fundação Oswaldo Cruz, Av. Brasil, 4365, 21040-360 Rio de Janeiro - RJ, Brasil Melissa Marsden

Escola Politécnica de Saúde Joaquim Venâncio, Fundação Oswaldo Cruz, Av. Brasil, 4365, 21040-360 Rio de Janeiro - RJ, Brasil Neila Guimarães Alves

Faculdade de Educação, Universidade Federal Fluminense, Rua Visconde do Rio Branco, 882, B1. D, Campus do Gragoatá, 24210-350 Niterói - RJ, Brasil

Recebido em 10/8/10; aceito em 1/2/11; publicado na web em 29/3/11

\begin{abstract}
PROBLEM-BASED LEARNING: A TEACHING TOXICOLOGY CHEMISTRY EXPERIENCE. This article describes a Problem-Based Learning (PBL) experience that taught organophosphorus pesticides chemistry, its human health effects and acetylcholinesterase assay to secondary students. The teaching process was based on a real intoxication case and ended with students' activities report presentation. The apparent lack of teacher reference and inexistence of a curriculum based on a strict textbook in which PBL is based on leads inexperienced students to insecurity and the idea that teachers are not doing there jobs. One way to minimize this situation is to use real cases in other to interest students as stakeholders of central problem solution.
\end{abstract}

Keywords: Problem-Based Learning; teaching; toxicology chemistry.

\section{INTRODUÇÃO}

Partindo das nossas experiências como docentes na Educação Básica e no Ensino Profissionalizante de Nível Médio, constatamos que os processos de ensino-aprendizagem que ainda predominam em nossas escolas apresentam características da chamada metodologia tradicional de ensino ou da "educação bancária", conforme caracterizada por Paulo Freire na obra Pedagogia do Oprimido. ${ }^{1}$ Para Freire, na educação bancária: "o educador é o que sabe; os educandos, os que não sabem"; "o educador é o que pensa; os educandos, os pensados"; "o educador é o que diz as palavras; os educandos, os que escutam docilmente" e, "o educador, finalmente, é o sujeito do processo; os educandos, meros objetos".

Assim como Paulo Freire, acreditamos que uma educação problematizadora deve substituir a educação bancária, habilitando os nossos estudantes a terem uma inserção crítica na realidade a partir do estímulo à criatividade e da reflexão. Portanto, defendemos que um projeto educacional que busque a construção da autonomia individual do aprendiz e que, concomitantemente, o torne consciente e responsável dentro da sua práxis na sociedade, deve empregar métodos que proporcionem variadas oportunidades de construção e reconstrução dos saberes e competências. Porém, devido ao método tradicional de ensino estar arraigado na prática docente, ainda é um grande desafio para nós educadores a elaboração e a aplicação permanente de ações educativas que privilegiem os conhecimentos prévios dos estudantes, que promovam a pesquisa em grupo e que forjem um ambiente investigativo de aprendizagem, através do surgimento de dúvidas, construção de hipóteses e experimentações.

*e-mail: renatoml@ fiocruz.br
Mitre e colaboradore ${ }^{2}$ situam as metodologias ativas de ensinoaprendizagem, dentre as quais a "Aprendizagem Baseada em Problemas" ou PBL (Problem-Based Learning), como abordagens pedagógicas que vêm sendo empregadas para a formação de um profissional capaz de desenvolver a habilidade de "aprender a aprender", termo que abrange o aprender a conhecer, o aprender a fazer, o aprender a conviver e o aprender a ser.

Rikers e De Bruin $^{3}$ consideram a PBL como uma das mais proeminentes protagonistas do construtivismo. Trabalhar o ensino de química com a utilização de problemas pode contribuir para o desenvolvimento das capacidades intelectuais dos estudantes. O ensino por problemas caracteriza-se por ser uma estratégia que permite aos estudantes terem uma ação proativa na sua educação científica. ${ }^{4}$ Ademais, a PBL e suas variantes, como o método de aplicação do "Estudo de Caso", têm o grande potencial de minimizar a grande fragmentação, a linearidade e o excessivo individualismo que constantemente permeiam os currículos dos cursos de graduação em Química. ${ }^{5}$

Ressaltamos que a PBL pode ser utilizada como estratégia didática ou, em uma aplicação mais abrangente, como um método de estruturação do currículo. No Brasil, o uso da PBL na estruturação curricular é mais comum em instituições de ensino superior, dentre as quais podemos mencionar: a Escola de Artes, Ciências e Humanidades da Universidade de São Paulo (SP); a Faculdade de Medicina da Universidade Estadual de Londrina (PR); a Faculdade de Medicina de Marília (SP); a Faculdade de Medicina do Centro Universitário Serra dos Órgãos (RJ) e o curso de Medicina da Universidade Federal de São Carlos (SP). Porém, na Educação Profissional brasileira, o emprego desta metodologia de ensino ainda é muito incipiente. Um reflexo deste fato é a escassez de trabalhos publicados sobre o uso de PBL nesta modalidade de ensino, devendo ser destacado o trabalho 
de Andrade e Campos. ${ }^{6}$ Outro aspecto fundamental a ser destacado é a falta de publicações específicas na língua portuguesa sobre PBL para a sua aplicação na Educação Básica ou Profissionalizante, assim como para a formação de professores destas modalidades de ensino. ${ }^{7}$

\section{A situação problema e a PBL}

A elaboração de um bom problema, ou situação problema, é fundamental para o êxito da PBL. Os problemas devem ser construídos com objetivos previamente determinados e, sempre que possível, tomando exemplos da vida real. Além disto, devem suscitar os conhecimentos prévios dos estudantes e estar relacionados com as suas futuras práticas profissionais. ${ }^{8}$

Perrenoud ${ }^{9}$ destaca a situação problema como um recorte de uma realidade, de um cenário complexo, de algo que é dinâmico. Uma das características marcantes de uma situação problema é desafiar o aprendiz para agir no intuito de transpor um obstáculo e realizar uma aprendizagem. Com outras palavras, Philippe Meirieu define a situação problema como uma "situação didática" na qual é proposta ao sujeito uma tarefa que só terá sucesso se o mesmo realizar uma aprendizagem. Esta aprendizagem, que é o verdadeiro objetivo da situação problema, se dá quando determinados obstáculos são superados na realização da tarefa proposta. ${ }^{10}$ Neste contexto, podemos conceber que a construção de uma situação-problema deve visar o trabalho do aprendiz dentro do que Lev Vygotsky ${ }^{11}$ definiu como "Zona de Desenvolvimento Proximal":

“A zona de desenvolvimento proximal é a distância entre o nível de desenvolvimento real, que se costuma determinar através da solução independente de problemas, e o nível de desenvolvimento potencial, determinado através da solução de problemas sob a orientação de um adulto ou em colaboração com companheiros mais capazes".

A PBL surgiu no final da década de 60 na Faculdade de Medicina da Universidade McMaster, na cidade de Hamilton, Canadá. Esta estratégia de estruturação de currículo foi criada com o intuito de superar a defasagem entre os anos iniciais do curso, caracterizados por uma formação dominantemente teórica, e o início da prática médica dos seus acadêmicos. A construção curricular por PBL permitiu que se estabelecesse uma relação de prática/teoria/prática como processo de formação dos médicos desta universidade. Recentemente, no início do ano letivo 2006-2007, o currículo de medicina da McMaster sofreu alterações para consolidar os seguintes aspectos educacionais: a ênfase no pensamento conceitual e na resolução de problemas; a ampliação das competências profissionais do currículo para priorizar o profissionalismo e as habilidades de comunicação; a melhora da interdisciplinaridade no processo de aprendizagem acadêmica e clínica; o aumento das oportunidades de colaboração entre diferentes profissionais e, o aumento da capacitação no uso de novas tecnologias. ${ }^{12}$

A PBL tem na situação problema o seu componente fundamental. ${ }^{13} \mathrm{O}$ problema, portanto, é o ponto de partida e conduz o processo de aprendizagem, que é organizado em ciclos estruturados de atividades.

A Figura 1 descreve os principais passos do ciclo de aprendizagem da PBL, que pode ser denominado de Processo Tutorial. ${ }^{14}$ Primeiro os estudantes são apresentados ao cenário de um problema. A utilização da ideia de cenário é adequada. Em muitos casos, no ensino das profissões da área da Saúde, os estudantes não possuem possibilidades de se defrontarem com situações reais. $\mathrm{Na}$ atividade desenvolvida, por exemplo, os estudantes não tiveram acesso a uma amostra de agrotóxico sem rótulo, conforme veremos a seguir.

Em um segundo momento eles devem analisar e reformular o problema, identificando fatos relevantes do cenário. Esta etapa auxilia

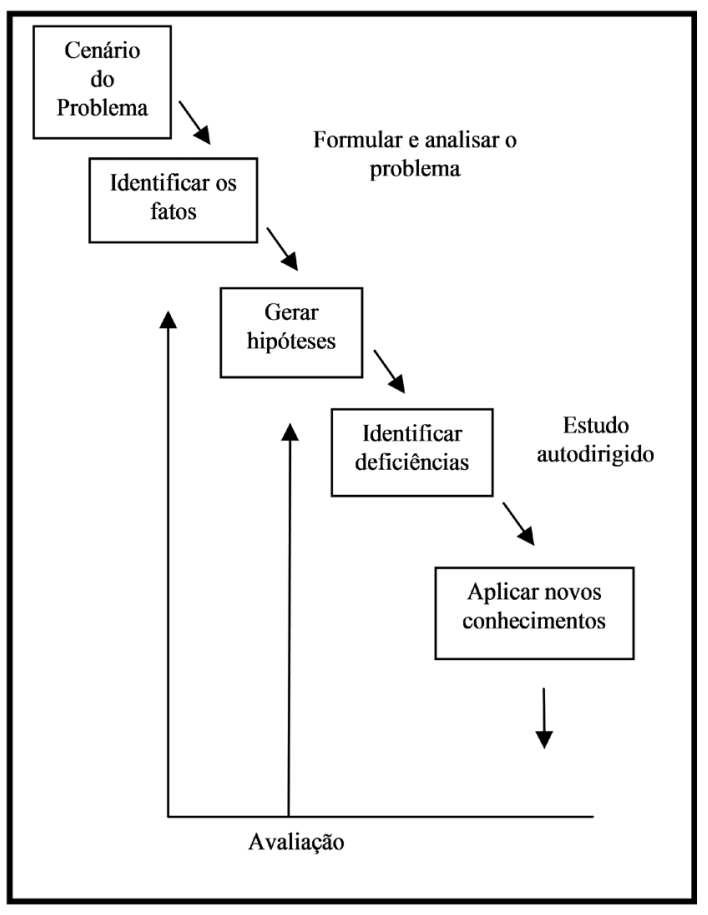

Figura 1. O ciclo de aprendizagem na PBL. Adaptado da ref. 14

os estudantes na representação do problema, fazendo-os entender melhor os fatos envolvidos e fazendo-os gerar hipóteses para possíveis soluções. Uma parte importante deste ciclo é a identificação das deficiências de conhecimento do grupo que dificultam, ou impedem, a proposição de soluções para o problema. Esta conclusão sobre as deficiências, feita em grupo e com foco na solução do problema central já identificado, gera uma etapa de estudos autodirigidos.

Em seguida, cada estudante deverá aplicar os novos conhecimentos oriundos do momento individual de aprendizagem na solução coletiva do problema. Ao final de cada ciclo, ou de cada problema, os estudantes precisam refletir sobre os conhecimentos que foram adquiridos no processo. Portanto, a PBL pode ser empregada como uma abordagem instrucional que auxilia os estudantes a desenvolver estratégias de aprendizagem mais flexíveis e a construir conhecimentos duradouros.

\section{DESENVOLVIMENTO}

\section{A aplicação da PBL}

A Escola Politécnica de Saúde Joaquim Venâncio (EPSJV), unidade técnico-científica da Fundação Oswaldo Cruz (FIOCRUZ), desenvolve atividades de pesquisa e ensino no campo da Educação Profissional em Saúde, formando trabalhadores de nível fundamental e médio. A EPSJV concebe o trabalho em saúde como "um trabalho reflexivo no qual as decisões a serem tomadas [pelos trabalhadores] implicam na articulação de saberes que provêm de várias instâncias, como as bases científicas e instrumentais, com ênfase no conhecimento científico, das bases tecnológicas, com ênfase no conhecimento técnico e nas qualificações tácitas do indivíduo e que são mediados pela dimensão ética e política". ${ }^{15}$

É neste contexto que o presente trabalho foi desenvolvido com a aplicação experimental da PBL. O objetivo principal foi o ensino da Química aplicada à Toxicologia para uma turma de 16 estudantes do segundo ano da Habilitação Técnica em Análises Clínicas da EPSJV, curso este que é integrado ao Ensino Médio. Esta experiência teve como principal objetivo fazer com que os estudantes apreendessem e 
construíssem conhecimentos essenciais (conceituais) sobre pesticidas. Alguns temas principais que teriam que ser abordados pelos estudantes eram: (a) efeitos toxicológicos de pesticidas organofosforados sobre a saúde humana e (b) dosagem da enzima acetilcolinesterase, ferramenta bioquímica para indicar a exposição humana aos pesticidas organofosforados e carbamatos. Além disto, o uso desta metodologia de ensino também visou alcançar objetivos nas áreas cognitivas, no desenvolvimento de habilidades e no comportamento dos estudantes. Isto porque a PBL é uma abordagem instrucional centrada no aprendiz que o potencializa para conduzir atividades de pesquisa, de integração de conhecimentos teóricos e práticos e de aplicação de estratégias e conhecimentos para desenvolver uma solução viável para um problema definido. ${ }^{16}$

Seguindo as orientações propostas por Robert Delisle, no livro "Como realizar a aprendizagem baseada em problemas", ${ }^{17} \mathrm{o}$ processo de ensino foi desenvolvido através das seguintes fases: 1) estabelecimento de relações com o problema; 2) estabelecimento de uma estrutura ou plano de trabalho para a resolução do problema; 3) construção de abordagens do problema; 4) re-equacionamento do problema; 5) elaboração e apresentação dos produtos.

As três primeiras etapas foram desenvolvidas na aula inicial com duração de $3 \mathrm{~h}$. A quarta etapa foi realizada uma semana depois e a última etapa na semana subsequente. Assim, a experiência de aplicação da PBL teve uma duração de 3 semanas e um total de $9 \mathrm{~h}$ de trabalho com os estudantes.

\section{Fase 1 - Estabelecendo relações com o problema}

Esta etapa consistiu em gerar motivação intrínseca nos aprendizes, fazendo com que os mesmos percebessem que é importante dedicar seu tempo e estar atento aos diferentes aspectos da resolução do problema apresentado. Uma das maneiras de fazer isto é a leitura e discussão de algum texto que apresente tópicos que sejam ligados ao problema de modo concreto. No desenvolvimento do nosso trabalho optamos por iniciar conversando com os estudantes sobre quais informações e conhecimentos prévios eles já possuíam sobre defensivos agrícolas, agroquímicos, agrotóxicos ou pesticidas, incluindo conhecimentos que por ventura eles tivessem sobre os riscos de intoxicação do homem e dos impactos ao meio ambiente causados por estas substâncias. As respostas orais foram variadas, tendo como fonte, em geral, programas de TV (noticiários, programas ecológicos, de produção agropecuária, etc.), além de jornais e revistas. Após estes primeiros instantes, informamos aos estudantes que o consumo de agrotóxicos vem crescendo nas últimas décadas no Brasil, transformando o país em um dos líderes mundiais no consumo destas substâncias. A importância econômica deste mercado no País foi mensurada e apresentada aos estudantes através de informações obtidas da Associação Brasileira da Indústria Química. ${ }^{18}$ Em 2007, o faturamento da indústria brasileira de agrotóxicos foi de 5,4 bilhões de dólares e em 2009 estes valores atingiram 6,3 bilhões de dólares.

Posteriormente, passamos aos estudantes alguns dados sobre intoxicação e envenenamento no Brasil. Para tanto, foram usados os registros do Sistema Nacional de Informações Tóxico-Farmacológicas, o SINITOX,${ }^{19}$ vinculado ao Centro de Informação Científica e Tecnológica (CICT) da FIOCRUZ, e um artigo científico que trata da intoxicação por agrotóxicos no Brasil. ${ }^{20}$ Por fim, apresentamos alguns dados sobre intoxicação no Brasil e a situação problema através de um texto distribuído aos estudantes (Figura 2).

\section{Fase 2 - Estabelecendo uma estrutura ou plano de trabalho para a resolução do problema}

Delisle ${ }^{17}$ sugere a construção de um quadro para ser usado como instrumento de delineamento do trabalho a ser desenvolvido pelos estudantes. Este quadro é composto de quatro colunas que são preen-

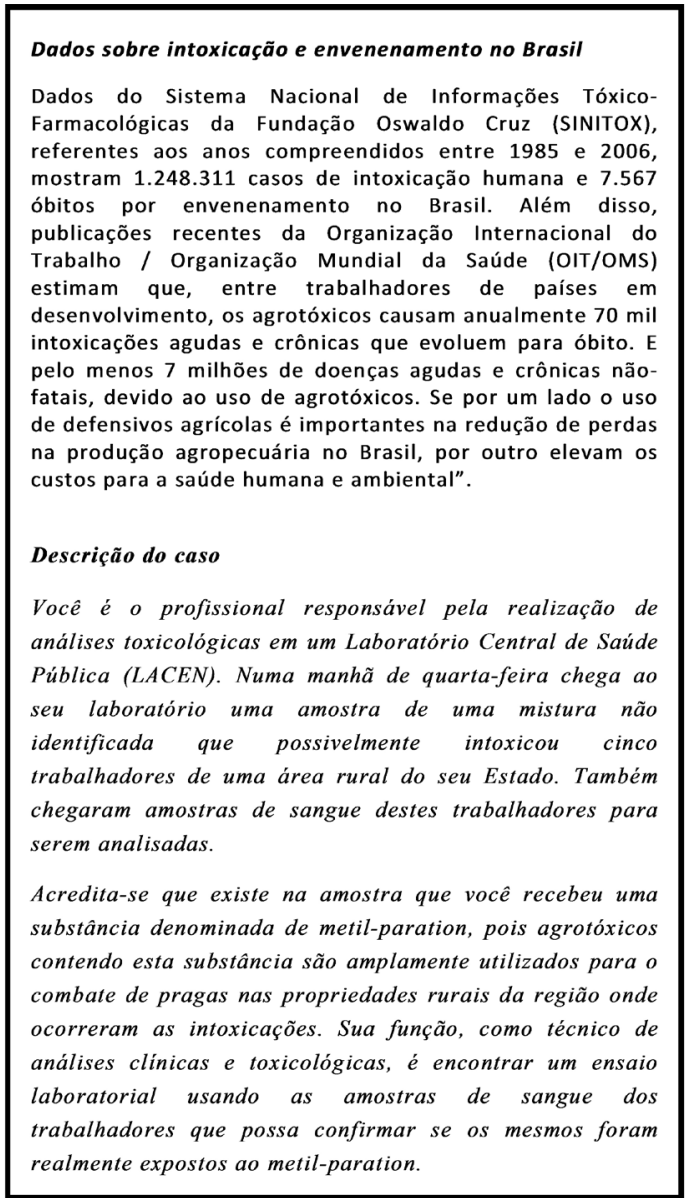

Figura 2. Texto encaminhado aos estudantes com a descrição da situação problema

chidas da esquerda para a direita (Figura 3). É sempre bom relembrar, no entanto, que embora os estudantes sejam os responsáveis pela resolução do problema apresentado, o professor atua como "professor orientador" do processo, intervindo sempre que necessário para conduzir a aprendizagem de acordo com os objetivos a serem alcançados.

A primeira coluna do quadro foi preenchida depois que foi solicitado aos aprendizes que dessem "Ideias" para solucionar o problema, estimulando o envolvimento de todos na discussão e aproveitando os conhecimentos já existentes entre os integrantes de cada grupo. Preenchida a primeira coluna, a segunda começou a ser elaborada e a intitulamos de "Fatos" ou, em outras palavras, "o que você sabe sobre pesticidas?" Com base nesta discussão, os estudantes listaram informações que obtiveram através da exposição do problema e a partir dos seus conhecimentos prévios sobre o assunto. Uma vez preenchida esta segunda coluna, foi possível seguir para a terceira coluna, denominada “Questões de Aprendizagem”. Neste espaço, os estudantes tiveram que listar os aspectos que precisavam de maior investigação, elaboração, definição. Ou seja, nesta coluna foram listados os aspectos que precisavam ser aprofundados para que fosse possível encontrar as soluções para o problema apresentado. Esta coluna é fundamental para o direcionamento das pesquisas e aprendizagens que serão realizadas pelos aprendizes, dando-lhes segurança e norteando suas investigações. A última coluna, intitulada de "Plano de Ação", foi construída a partir do registro do modus operandi dos aprendizes na busca de como realizar as suas investigações. A Figura 3 foi construída com algumas frases dos estudantes para as três primeiras colunas.

Após o preenchimento destas três colunas, os estudantes foram organizados em 4 grupos de 4 indivíduos e, nesta nova configuração, 


\begin{tabular}{|c|c|c|c|}
\hline Id eias & Fatos & $\begin{array}{c}\text { Questões de } \\
\text { Aprendizagem }\end{array}$ & $\begin{array}{c}\text { Plano } \\
\text { de Ação }\end{array}$ \\
\hline $\begin{array}{l}\text { Fazer testes } \\
\text { analíticos na } \\
\text { amostra da } \\
\text { mistura. } \\
\text { Fazer uma } \\
\text { eletroforese } \\
\text { com a } \\
\text { amostra de } \\
\text { sangue. } \\
\text { Analisar a } \\
\text { composição } \\
\text { química dos } \\
\text { pesticidas } \\
\text { mais } \\
\text { utilizados no } \\
\text { local para } \\
\text { detectar a } \\
\text { presença de } \\
\text { metilparation } \\
\text { neles. } \\
\text { Verificar as } \\
\text { condiçôes de } \\
\text { trabalho } \\
\text { desses } \\
\text { trabalhadores } \\
\text { rurais. } \\
\text { Procurar um } \\
\text { teste } \\
\text { bioquímico } \\
\text { ou } \\
\text { toxicológico } \\
\text { específico. } \\
\text { Analisar } \\
\text { vestígios do } \\
\text { veneno nas } \\
\text { plantações e } \\
\text { analisar o } \\
\text { ambiente. }\end{array}$ & $\begin{array}{l}\text { O uso } \\
\text { indiscriminado de } \\
\text { pesticidas pode } \\
\text { produzir pragas } \\
\text { cada vez mais } \\
\text { resistentes. } \\
\text { Pesticidas inibem } \\
\text { enzimas e alteram } \\
\text { o metabolismo. } \\
\text { Pesticidas são } \\
\text { tóxicos e podem } \\
\text { ser divididos em } \\
\text { dois grupos: } \\
\text { organoclorados e } \\
\text { organofosforados. } \\
\text { Combatem pestes } \\
\text { nas plantações e } \\
\text { também em } \\
\text { nossas casas, } \\
\text { como os remédios } \\
\text { contra mosquitos } \\
\text { e baratas. } \\
\begin{array}{l}\text { Pesticidas } \\
\text { contaminam o } \\
\text { meio ambiente e } \\
\text { prejudicam a } \\
\text { saúde humana. }\end{array}\end{array}$ & $\begin{array}{l}\text { Preciso saber o } \\
\text { que é } \\
\text { metilparation e } \\
\text { seus efeitos no } \\
\text { homem. } \\
\text { O metilparation } \\
\text { pode ativar ou } \\
\text { inativar alguma } \\
\text { enzima? } \\
\text { Como o } \\
\text { metilparation } \\
\text { entra no } \\
\text { organismo? Ele } \\
\text { é persistente no } \\
\text { meio ambiente? } \\
\text { Quais são a } \\
\text { fórmula química } \\
\text { e os efeitos do } \\
\text { metilparation? } \\
\text { Como é o dia-a- } \\
\text { dia do } \\
\text { trabalhador rural } \\
\text { e como ele } \\
\text { aplica o } \\
\text { pesticida na } \\
\text { lavoura? } \\
\text { Preciso saber } \\
\text { um método para } \\
\text { identificar a } \\
\text { substância no } \\
\text { corpo. }\end{array}$ & $? ? ?$ \\
\hline
\end{tabular}

Figura 3. Estruturação de um plano de trabalho para a resolução do problema. Este quadro foi apresentado aos estudantes no início do módulo e os alunos foram preenchendo cada coluna, uma de cada vez, sob orientação do professor

partimos para a próxima etapa do processo de aprendizagem.

\section{Fase 3 - Construindo as abordagens do problema}

Esta etapa buscava garantir a construção de um método ou mecanismo objetivo e eficiente da solução do problema apresentado a partir da prática de uma aprendizagem de cunho colaborativo e solidário. A turma em que esta experiência foi desenvolvida possuía 16 estudantes, e optamos pela formação de 4 grupos com 4 integrantes. Cada grupo se organizou para definir e analisar propostas para a resolução da situação problema. O debate no interior do grupo, com atuação do professor supervisionando e orientando este processo, permitiu que cada integrante pudesse reavaliar seus conhecimentos prévios e também possibilitou um exercício de aprimoramento na elaboração das questões de aprendizagem. Como efeito, permitiu a seleção das questões mais pertinentes ao problema proposto. Coube a cada grupo formado preencher a coluna intitulada Plano de Ação, elaborando as estratégias para coletar informações pertinentes à resolução do problema. As propostas formuladas estão descritas na Figura 4.

O próximo passo foi a realização do estudo individual. Foi explicado aos estudantes que, embora a solução seja do grupo, o momento de estudo individual é fundamental. Este momento permite que cada indivíduo use a sua autonomia para buscar as informações, da forma

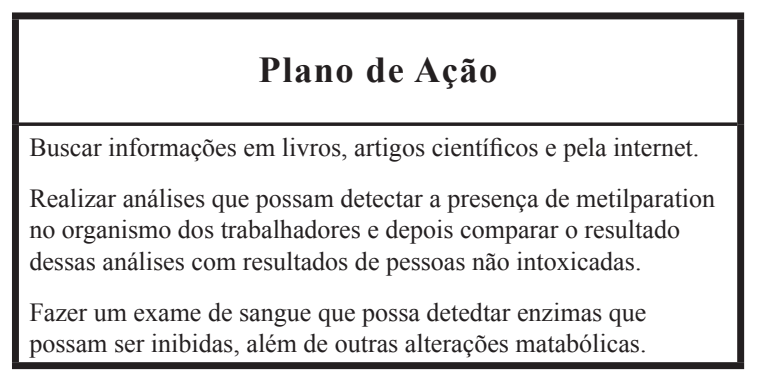

Figura 4. Propostas apresentadas para o plano de ação. Esta é a última coluna do quadro apresentado na Figura 3, que foi a última a ser preenchida pelos estudantes

que acreditar ser a mais adequada para que possa compartilhar as informações com os seus companheiros. Os estudantes tiveram o prazo de uma semana para estudarem por conta própria, se reunirem novamente para re-equacionar o problema e prepararem uma pequena apresentação oral do processo de trabalho em grupo e dos conhecimentos apreendidos.

\section{Fase 4 - Re-equacionando o problema}

$\mathrm{Na}$ semana seguinte, após o trabalho individual e coletivo dos estudantes, cada grupo apresentou aos demais um relatório do trabalho desenvolvido. Este relatório se transformou em um dos instrumentos de avaliação, tendo como critérios os recursos utilizados para investigar as questões de aprendizagem, a pertinência do plano de ação desenvolvido para o alcance das soluções e os conhecimentos adquiridos pelos indivíduos e grupos.

Através da troca de informações contidas nos relatórios e debates, foi sugerido aos grupos que fizessem uma nova avaliação de todo o processo de estruturação do trabalho desenvolvido para a resolução do problema. Foi possível considerar a manutenção e a exclusão de ideias iniciais, a apreensão de novos conhecimentos, a inserção (se necessário) de novas questões de aprendizagem e a reformulação das estratégias do plano de ação. Após estas discussões, cada grupo teve mais uma semana para preparar uma apresentação final do trabalho, ou seja, a resolução da situação problema.

É importante destacarmos que o professor atuou nesta etapa com sugestões, levantando outras questões e tirando algumas dúvidas de maior complexidade. O professor que se utiliza da PBL possui a difícil tarefa de orientar os estudantes, porém, sem determinar rigidamente o percurso de aprendizagem dos mesmos.

\section{Fase 5 - Elaborando e apresentando os produtos}

A PBL é caracterizada por apresentar princípios de avaliação que buscam ultrapassar o uso de provas, testes e outros instrumentos de mensuração da memorização de conteúdos. O uso desta metodologia exige a substituição do paradigma das avaliações somativas para o da avaliação formativa. Neste último, o processo avaliativo tem como enfoque os aspectos da aprendizagem, em suas dimensões cognitivas, afetivas e relacionais. Portanto, a avaliação diagnóstica dos conhecimentos prévios dos estudantes, realizada no primeiro dia de aula de aplicação da PBL; a capacidade e a evolução da autonomia e da organização dos estudantes para resolver situações complexas; a capacidade de desempenhar trabalhos em grupos (onde surgem divergências de opiniões); o incremento de competências para se fazer compreender em comunicações orais e escritas; a ampliação da responsabilidade por parte do próprio aprendiz no seu processo de aprendizagem e o desenvolvimento da sua capacidade de aprender a aprender, são aspectos valiosos na avaliação da aprendizagem quando do uso de metodologias ativas de ensino. 
Neste trabalho, optamos em realizar um percurso avaliativo que fosse estruturado a partir do olhar do estudante sobre o seu próprio processo de aprendizado, da autoavaliação, da heteroavaliação pelos colegas do grupo, além da avaliação realizada pelo professor. Para tanto, foi solicitada aos estudantes a elaboração de um documento escrito no qual deveriam explicitar os conhecimentos que foram adquiridos com a experiência relatada, as dificuldades enfrentadas por trabalharem com a estratégia da PBL e uma autocrítica sobre o seu próprio desempenho dentro do grupo de trabalho, além de comentários sobre a participação dos demais integrantes.

A avaliação pelo professor orientador se deu através de observações, pareceres escritos e leitura dos documentos apresentados pelos estudantes. Dentro deste contexto, acreditamos também ser producente e adequado apresentarmos um compilado das informações trazidas para discussão acerca da resolução da situação problema em questão, além dos conhecimentos que foram construídos e apresentados ao longo do processo de aprendizagem. Vale lembrar que os objetivos da atividade de ensino desenvolvida, no que tange aos chamados conteúdos conceituais, eram fazer com que os aprendizes adquirissem conhecimentos a respeito dos pesticidas organofosforados. Estes conhecimentos teriam que incluir aspectos sobre as estruturas químicas e os efeitos nocivos da exposição humana a estes compostos, assim como sobre a aplicação das determinações das atividades das colinesterases como biomarcadores da exposição e intoxicação do homem a tais pesticidas.

\section{Uma avaliação da situação problema}

\section{Conhecimentos adquiridos sobre pesticidas}

Os estudantes descobriram que os compostos organofosforados surgiram em 1936, a partir de pesquisas do químico alemão Gerhald Schrader, sendo empregados para fins militares. Viram que os anos compreendidos entre 1940 e 1960 foram muito produtivos no descobrimento e síntese de compostos químicos orgânicos. Identificaram que a utilização em larga escala de pesticidas, como componentes importantes em sistemas de manejos de pragas e no controle de vetores de doenças, ocorreu a partir de 1940. Além disto, tomaram conhecimento de que o uso do DDT (diclorodifeniltricloroetano), que faz parte do grupo dos pesticidas organoclorados, ocorreu a partir de 1939, através dos trabalhos do químico suíço Paul Müller. Um dos grupos de estudantes trouxe, inclusive, uma discussão a respeito da obra de Rachel Carson, Silent Spring (Primavera Silenciosa) de 1962, na qual a autora norteamericana fez denúncias sobre os perigos da acumulação do DDT no meio ambiente.

No decorrer das discussões, foi sugerido aos estudantes que visitassem o endereço eletrônico da Agência de Proteção Ambiental dos Estados Unidos (EPA), onde pode ser encontrada uma definição de pesticida, a saber: Um pesticida é qualquer substância ou mistura de substâncias utilizadas para prevenir, destruir, repelir ou mitigar qualquer praga. As pragas incluem insetos, roedores, ervas daninhas, fungos, bactérias, vírus, e até príons (tema que os estudantes investigaram posteriormente).

A EPA classifica os pesticidas químicos em organofosforados, carbamatos, organoclorados e piretroides. Deste modo, os estudantes verificaram que pesticidas não são classificados apenas como organoclorados ou organofosforados, assim como posteriormente viram que os piretroides são geralmente usados como inseticidas domésticos para o combate de baratas, pernilongos e outros insetos.

\section{Conhecimentos adquiridos sobre pesticidas organofosforados e as colinesterases}

A partir das pesquisas e estudos, os estudantes verificaram que os organofosforados são compostos orgânicos que contêm um átomo de fósforo em sua estrutura química, sendo muito empregados no combate de pragas em culturas agrícolas por serem relativamente baratos e apresentarem um amplo espectro de ação sobre diferentes pestes. $\mathrm{O}$ professor trouxe como informações complementares o fato de muitos dos inseticidas contendo fósforo ou são derivados do ácido fosfórico ou do ácido tiofosfórico. Estas substâncias podem ser representadas pela fórmula geral apresentada na Figura 5, onde os radicais R1 e R2 podem ser metil ou etil. Dependendo da configuração dos átomos de oxigênio ou enxofre, seis grupos principais de organofosforados podem ser distinguidos. ${ }^{21}$

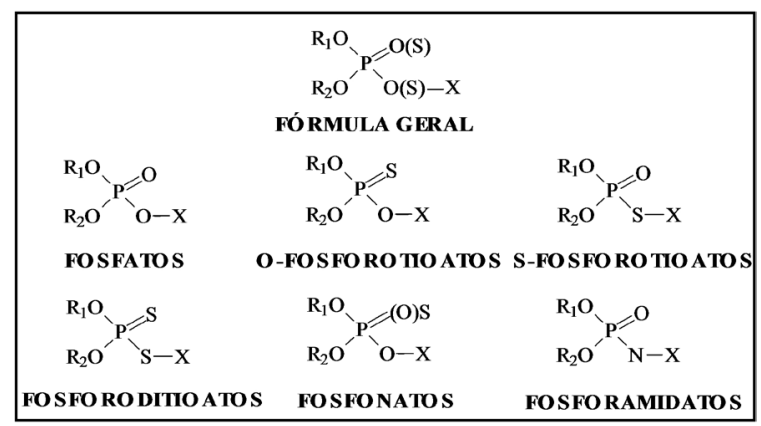

Figura 5. Estruturas químicas dos principais grupos de pesticidas organofosforados. Adaptada da ref. 21

A exposição do organismo humano aos organofosforados ocorre através de ingestão, inalação e/ou absorção cutânea, sendo estas duas últimas vias de intoxicação as mais comuns entre os trabalhadores responsáveis pela aplicação do produto no campo, assim como entre os trabalhadores responsáveis pela manufatura e formulação destes produtos nas indústrias. Portanto, a ideia apresentada pelos estudantes de verificar as condições de trabalho destes trabalhadores rurais foi explorada no sentido de alertá-los quanto à importância do uso de equipamentos de proteção individual (EPI) e de respeito às normas vigentes de segurança nos diferentes ambientes de trabalho.

Quanto à ação do metilparation no organismo, pesticida citado na situação problema (Figura 2), os estudantes também aprenderam que este composto sofre um processo de biotransformação no fígado, formando metilparaoxon, um metabólito muito mais tóxico do que o composto original. A ativação do metilparation ocorre através da dessulfuração oxidativa do grupo tiofosfato $(\mathrm{P}=\mathrm{S})$, que se converte em seu oxon-análogo (grupamento $\mathrm{P}=\mathrm{O}$ ). A dessulfuração é catalisada pelo sistema de mono-oxigenases hepáticas do sistema do citocromo P450.

Como futuros profissionais da Saúde, foi relevante o fato dos estudantes compreenderem que a ação tóxica predominante dos organofosforados é a inibição irreversível de várias enzimas, especialmente da acetilcolinesterase (AChE, EC 3.1.1.7). A AChE é encontrada predominantemente nos eritrócitos, nervos e músculos, atuando nas sinapses colinérgicas, enquanto outra colinesterase, chamada de butirilcolinesterase ou pseudocolinesterase (BChE, EC 3.1.1.8), é encontrada principalmente no fígado, de onde é secretada para o plasma. ${ }^{22}$

Como consequência da inibição da $\mathrm{AChE}$, ocorre o acúmulo da acetilcolina nas terminações nervosas e o indivíduo apresenta, dentre outros, os seguintes sintomas, no caso de uma intoxicação aguda: suor e salivação abundante, lacrimejamento, fraqueza, visão turva, pupila contraída, vômitos, dificuldade respiratória, ataxia, tremores musculares e convulsões. Foi informado aos estudantes que um efeito crônico da intoxicação por organofosforados consiste na chamada polineuropatia retardada, caracterizada por ataxia e paralisia muscular, que ocorre 2 ou 3 semanas após a exposição a estes compostos. ${ }^{23}$

Considerando que a inibição da atividade das colinesterases é específica para detectar exposições por organofosforados, os 
estudantes concluíram que a inibição das mesmas é adequada para indicar a exposição humana a estes pesticidas. Além disto, os estudantes concluíram que a inibição das colinesterases também pode ser empregada para investigar possíveis intoxicações por compostos carbamatos, uma vez que as substâncias que pertencem a este grupo também inibem a $\mathrm{AChE}$ e a BChE. Ressaltamos que a aplicação destas enzimas como biomarcadores de exposição e efeito desses pesticidas estava contemplada como um dos conteúdos do programa da disciplina ministrada (Toxicologia).

Para que os estudantes pudessem ir ao laboratório para determinar a atividade da $\mathrm{AChE}$ ou $\mathrm{BChE}$, foi explicado que as colinesterases podem ter a sua atividade medida utilizando um sistema colorimétrico que consiste na avaliação da hidrólise de um substrato derivado de tiocolina, que gera um radical sulfidrila $(\mathrm{SH})$ por ação da enzima. Esta sulfidrila reage espontaneamente com o ácido 5,5'-ditiobis-2nitrobenzoico (DTNB) levando à formação de um composto amarelo, o ácido tionitrobenzoico (TNB), que pode ser medido em um espectrofotômetro ajustado para o comprimento de onda de $410 \mathrm{~nm} .^{24}$

Os estudantes ficaram motivados para realizar determinações das colinesterases em soro ou plasma. Um grupo trouxe para discussão a possibilidade de se fazer uma cromatografia com a amostra que possivelmente teria intoxicado os trabalhadores. A cromatografia é uma poderosa técnica analítica, capaz de comprovar a presença ou ausência do metilparation na substância contida no frasco não rotulado que chegou ao laboratório. Embora não tivéssemos como objetivo explorar as técnicas de cromatografia, esta resposta trazida pelos aprendizes serviu para que fosse despertada em toda a turma a curiosidade sobre os fundamentos desta técnica e de como ela poderia ser empregada em laboratórios para a realização de análises clínicas e toxicológicas.

\section{CONSIDERAÇÕES FINAIS}

O uso de metodologias de ensino e de avaliação que estimulem a iniciativa dos estudantes está contemplado na Lei de Diretrizes e Bases da Educação Nacional - LDB (Lei No. 9.394 de 1996). Considerando-se a integração entre Ensino Médio e Profissional, no que concerne às competências e habilidades de um profissional de Técnicas Laboratoriais de Análises Clínicas em Saúde, as mesmas devem abranger a capacidade de realizar conexões entre os conhecimentos científicos e a complexidade do seu campo profissional, rompendo com a dicotomia entre teoria e prática, entre trabalho manual e intelectual. Caso contrário, aumenta-se o risco de se gerar um profissional capaz de realizar técnicas de análise e diagnóstico existentes em um manual ou protocolo de modo mecânico, sem competência para refletir acerca dos seus processos e do contexto do seu trabalho na Saúde Pública.

A experiência apresentada neste artigo nos convenceu que é possível aplicar a PBL na Educação Profissional, apesar das dificuldades dos estudantes em lidar com a construção de seu próprio processo de aprendizagem. A perda dos referenciais gerados pelos programas rígidos, baseados no livro texto, coloca os estudantes numa posição de insegurança com a falsa aparência de que os professores não estão trabalhando. A melhor forma de lidar com esta situação é a construção de situações baseadas na vida real que possam colocar os estudantes como parte interessada na solução do problema central.
Acreditamos que a PBL, como metodologia de ensino, deve ser aplicada como um paradigma curricular nas modalidades de ensino profissional e não apenas em algumas disciplinas e de modo esporádico. Cursos estruturados tendo como base a PBL favorecem a construção, a apreensão e a integração de conhecimentos de diferentes campos disciplinares (interdisciplinaridade), além de propiciar a possibilidade de colocar os estudantes no cerne do processo educativo, conferindo-lhes maior autonomia e responsabilidade no seu próprio aprendizado.

\section{REFERÊNCIAS}

1. Freire, P.; Pedagogia do Oprimido, $44^{\mathrm{a}}$ ed., Editora Paz e Terra: Rio de Janeiro, 2005.

2. Mitre, S. M.; Siqueira-Batista, R.; Girardi-De-Mendonca, J. M.; de Morais-Pinto, N. M.; Meirelles, C. D. B.; Pinto-Porto, C.; Moreira, T.; Hoffmann, L. M. A.; Ciênc. Saúde Colet. 2008, 13, 2133.

3. Rikers, R. M. L. P.; Bruim, A. B. H.; Adv. Health Sci. Educ. 2006, 11, 315.

4. Silva, S. F.; Núñez, I. B.; Quim. Nova 2002, 26, 1197.

5. Sá, L. P.; Francisco, C. A.; Queiroz, S. L.; Quim. Nova 2007, 30, 731.

6. Andrade, A. B. S. A.; Campos. L. M. L.; Anais do VI Encontro Nacional de Pesquisa em Educação em Ciências, Florianópolis, Brasil, 2007.

7. Silva Filho, M. V.; Lopes, R. M.; Alves, N. G.; Figueiredo, L. M. S.; Anais do Congresso Internacional PBL 2010, São Paulo, Brasil, 2010.

8. Lima, G. Z.; Linhares, R. E. C.; Rev. Bras. Educ. Méd. 2008, 32, 197.

9. Perrenoud, P.; Dez novas competências para ensinar, Editora Artmed: Porto Alegre, 2000.

10 Meirieu, P.; Aprender... sim, mas como?, Editora Artmed: Porto Alegre, 1998.

11. Vygotsky, L. S.; A formação social da mente, Editora Martins Fontes: Rio de Janeiro, 2007.

12. Branda, L. A. Em Aprendizagem Baseada em Problemas no Ensino Superior; Araújo, U. F.; Sastre, G., orgs.; Editora Summus: São Paulo, 2009, cap. 9.

13. Mamede, S.; Penaforte, J.; Schmidt, H.; Caprara, A.; Tomaz, J. B.; Sá, H. L. C.; Aprendizagem Baseada em Problemas: Anatomia de uma Abordagem Educacional, Editora Hucitec: Fortaleza, 2001.

14. Hmelo-Silver, C. E.; Educ. Psychol. Rev. 2004, 16, 235.

15. http://www.epsjv.fiocruz.br/upload/PesqProjetoDoc/projeto_politico _pedagogico.pdf, acessada em Julho 2010 e Março 2011.

16. Savery, J.; The Interdisciplinary Journal of Problem-Based Learning 2006, 1,9 .

17. Delisle, R.; Como realizar a aprendizagem baseada em problemas, $1^{\mathrm{a}}$ ed., Editora ASA: Lisboa, 2001.

18. http://www.abiquim.org.br, acessada em Julho 2010 e Março 2011.

19. http://www.fiocruz.br/sinitox, acessada em Julho 2008 e Março 2011.

20. Faria, N. M. X.; Fassa, A. G.; Facchini, L. A.; Ciênc. Saúde Colet. 2007, $12,25$.

21. Maroni, M.; Colosio, C.; Ferioli, A.; Fait, A.; Toxicol. 2000, 143, 5.

22. Massoulié, J.; Pezzementi, L.; Bon, S.; Krejci, E.; Vallette, F. M.; Prog. Neurobiol. 1993, 41, 31.

23. Jokanović, M.; Toxicol. 2001, 166, 139.

24. Ellman, G. L.; Courtney, K. D.; Andres Jr., V.; Featherstone, R. M.; Biochem. Pharmacol. 1961, 7, 88. 